Questioning the character and significance of convergence between social network and professional practices in teacher education

\author{
Corresponding author: Dr Keith Turvey
}

Address: University of Brighton, School of Education, Falmer, Brighton, BN1 9PH, UK. 


\title{
Questioning the character and significance of convergence between social network and professional practices in teacher education
}

\begin{abstract}
This paper captures and characterises the interplay between a group of student teachers' narratives of social network practice and their emergent professional practice with technologies. Teachers on an Initial Teacher Education (ITE) programme in the UK spent a semester studying a module that synthesised universitybased lectures with a professional intervention using online communications technologies in a local Primary School involving a class of 30 children (8-10 Years). A narrative methodology was developed to capture and conceptualise the teachers' perceptions of the experience. Teachers' dispositions towards the appropriation of technologies were found to be as ubiquitous across social network and professional contexts, as the technological tools themselves. However, the distinctly nuanced ways in which the teachers experienced the process of convergence raises questions with regards the significance of such convergence and how we both capture and characterise convergence as a technological, cultural or agent-centred process. The findings support the need for an agent-centred view of convergence embedded within the wider socio-cultural ecology that incorporates individuals' engagement with media and social network practices.
\end{abstract}

\section{From techno to teacher centricity}

In the United Kingdom, the last two decades have been characterised by a tendency towards techno-centric perspectives on the appropriation of technological tools to enhance pedagogy. During the previous 1997-2010 Labour Government's tenure, much policy (DfES, 2005: Becta, 2009) was focused on the potential of new technologies to 'transform' schooling, echoing Postman's claims that 'once a technology is admitted, it plays out its hand; it does what it is designed to do,' (1993, p.7). Whilst not refuting the fact that media and new technologies 'change[s] the mindscape of the user,' (McLuhan and Zingrone, 1995, p.9) and to a significant extent shape the potential scope and forms of human action and interaction (McLuhan, 1964), such techno-centric perspectives also negate the influence and agency that individuals exert as they appropriate technological tools according to their own 'concerns and ambitions' within particular socio-cultural contexts (Säljo, 2009, p.316). As Bruce and Hogan have also noted, technologies can equally play an important role in emancipation or 'reinscribe existing inequitable power relations' (1998, np). Thus, the aim of this paper is not to prove or indeed disprove some kind of causal link between teachers' informal use of social networking tools and their professional practice. Rather it is to explore some of the nuanced ways in which professional contexts and social network contexts inter-relate from a teacher-centred perspective. For the purpose of this paper I use the terms social network and social networking practices interchangeably, and more loosely than Boyd and Ellison (2008) to encapsulate the variable means by which agents use technologies including mobile devices to sustain and extend a complex ecology of connections through active engagement with networked communications.

Cuban's (2001) study of the introduction of 'new technologies' in schools in California's Silicon Valley questioned the assertions often made by policy makers 
regarding the potential of new technologies to transform pedagogy and education. The Silicon Valley teachers in the study who were able to integrate 'new technologies' into their 'instructional repertoire' proved to be the exception rather than the rule (Cuban, 2001, p. 53). A key point to note from Cuban's study is that all of the teachers remained in control to the extent that they all adopted an approach to the 'new technology' that enabled them to 'sustain rather than transform' the philosophical principles guiding their pedagogical actions. This suggests that what affects the way some teachers integrate technologies into their pedagogical practice and others not, is far more complex than a straightforward causal relationship between their professional use of technologies and how they make use of such technologies in their wider social and leisure lives. Despite this, Jenkins suggests that the cultural convergence brought about through the proliferation of new forms of mass communication remains significant in that, 'the skills we acquire through play may have implications for how we learn' (Jenkins, 2006, p.23). However, what are these implications and how do we capture them? Boyd and Ellis (2008, np) call, inter alia, for 'richer, ethnographic research' in order to 'aid scholars' ability to understand' the implications of social network tools and mobile technologies.

Consequently, I argue here that the influence of social network and mobile technologies, 'has to be established by observation, not proclaimed as fate,' (Sey and Castells, 2004, p.364). Moreover, such observations need to take into consideration actors' unique perspectives and agency over any process of technological appropriation in order to be 'more explicit about the complex and problematic nature of what it is that teachers know and how they come to know it' when integrating technological tools into their professional practice. (Fisher, Higgins and Loveless, 2006, p.8). This has implications for the kinds of conceptual approaches we adopt to encapsulate the multiple perspectives of new forms of mass media communication, and the agency that actors exert as they engage with such tools across different contexts; formal, informal, professional and social. Furthermore how do we characterise convergence? In order to begin to address these issues I define convergence from an agent-centred perspective, as a process towards congruent dispositions that individuals display across different contexts; the antithesis to this being incongruence between the dispositions that individuals adopt across different contexts. I will explore the rationale for this further now.

\section{Towards an agent-centred concept of convergence}

Cook, Pachler and Bachmair (2011) argue strongly for a cultural ecology theory of 'mobile and convergent mass communication' (p.181) in which agency is defined as actors' ability to appropriate technological tools to actively impact upon a range of socio-cultural contexts (Pachler, Cook and Bachmair, 2010). The strength of such a cultural ecology model of appropriation is that it offers the potential for a richer understanding of the process of technological appropriation than more techno-centric models that look to the affordance of technologies and contingencies for learning built into their design (Luckin et al, 2006), useful though these can be. In recognition of the interdependency, convergence and mobility of technological tool use between various socio-cultural contexts, Pachler et al question the validity and appropriateness of distinctions between sites of learning, proposing that 'from our cultural perspective, this division is increasingly artificial, even counterproductive' (2010, p.1). The constant blurring of cultural and institutional boundaries brought about by the 
'perpetual-contact' character of social and mobile network practices is a recurrent theme within the literature (Katz and Aakhus, 2002: Jenkins, 2006: Horst, 2008: Baron, 2008). Thus, arbitrarily categorising contexts of learning by site such as formal/informal, social/professional, virtual/face-to-face, is increasingly scrutinised and questioned. The interconnected and ubiquitous nature of the Internet and mobile technologies bring opportunities for authentic experiences and learning in whatever context. Such convergence it can be argued raises questions regarding out-dated notions of schooling as preparation for delayed entry into the 'real' world. Traditional context specific sites for schooling are seen as increasingly redundant as the 'fluidity, provisionality and instability' (Pachler et al, 2010, p.1) of the world is constantly made explicit and present to us through a permanently connected state of interaction with media. In such a state, the train compartment can become an office or a less than engaging lecture might provide opportunities to send some texts about a later social engagement; that is, contexts are in a constant process of convergence, challenging their established order and function. However focusing mainly on convergent contexts is also problematic for it could be argued that contexts have always converged, but such convergence has remained within the private space of the intra-psychological (Vygotsky, 1978: Wertsch, 1998). That is, individual's inner thought processes are not bound by context. This raises the question of whether such interconnectedness yielded by always-on (Baron, 2008) new mobile communications technologies and social networks represents a fundamental shift of paradigm or merely makes more explicit a process of agent-centred convergence that has always been present, just less visible. Indeed, if convergence is seen from a more agent-centred perspective, the ways in which individuals sustain 'a sense of their own identity across contexts' as they participate in multiple communities both online and offline, is significant (Wenger, White and Smith, 2009, p.59). Baron argues that the 'near real-time window on the world restructures our time together' $(2008$, p.7) and marks what she calls 'the end of anticipation' as people use mobile technologies to share their experiences in the moment rather than after the event. However, this assumes a common approach to the ways in which individuals appropriate such tools. Jenkins is more circumspect assigning evidence of convergence brought about as people exploit new modes of mass communication as part of 'a period of prolonged transition' (2008, p.11).

On the nature of convergence Jenkins reminds us that it 'refers to a process, not an end point' (Jenkins, 2006, p.16). Similarly, as Davydov suggests, all forms of communication 'exist only in the process of different kinds of activity realisation by people' (1999, p.47). Thus, is there a risk of becoming too focused on convergence as a phenomenon relating mainly to contexts as opposed to convergence as a cultural process enacted and experienced by agents appropriating tools? Jenkins distinguishes between technologies as delivery systems and media as cultural practice although both are inherently interrelated (Jenkins, 2006). Jenkins also gives less credence to the techno-centric obsession of developers with technological convergence implying that cultural convergence and the way that agents appropriate technological tools is of more significance. As noted, from this agent-centred perspective adopted in this paper I define convergence with regards the congruent dispositions that individuals display and sustain across different contexts both online and offline. However, this is not to deny the importance of context. I also adopt an ecological perspective arguing that any isolation of parts such as the technologies or specific cultural practices from the broader perspective or the individual at the centre of the process is of limited use in attempting to gain a fuller understanding of phenomena such as mobile technologies 
or social networks and their implications for education. There is little question that the technologies themselves 'enhance the level and degree of communication, leading individuals to communicate' across convergent contexts (Horst, 2008, p.2). However, as Wertsch argues 'any account of mediated action that focuses exclusively on one or another of these moments in isolation is bound to be incomplete, if not seriously misleading' (1998, p.74). Fuller (2005, p.1) also extrapolates in relation to media ecologies, that practices incorporating forms of technological communication and media 'set in play a process of mutual stimulation that exceeds what they are as a set.' Given such claims, teachers' use of online communications technologies within professional contexts need also to be viewed as constituent episodes within a broader narrative of technological appropriation in informal and leisure contexts. Such sociocultural and ecological perspectives which also give prominence to actors' individual agency, have led me to formulate a narrative ecology conceptual approach to the exploration of teachers' pedagogical development appropriating technological tools (Turvey, 2012), which I will discuss in the following sections.

\section{Methodology and conduct}

\section{Context and Participants}

In this paper I present two out of five within-case summaries in depth - Joe and Karen - before going onto a cross-case discussion, which also draws on some limited aspects of the other cases. Joe was in his early twenties (20 - 25 years) at the time of the study (2007 - 2008) and had entered University without any career breaks. In contrast, Karen was a mature student ( 30 - 35 years) whose route into Higher Education contrasted significantly to Joe and the others. Maria, Laura and Heather were also in their early twenties ( $20-25$ years) and like Joe had entered University without any significant career breaks since compulsory schooling. At the time of the study (20072008), the five participants were all in the third year of a four-year undergraduate degree leading to Qualified Teacher Status (QTS) in Primary Education in the UK with a subject specialism in ICT. It is recognised that in terms of social network practices this dates the study. However, according to a baseline survey conducted, all five student teachers were actively engaged with using social networks sites (SNS) such as Facebook and MSN, the likes of which continue to dominate the social network landscape. From this perspective I believe the study remains valid. Fourteen student teachers in all were enrolled in the module, which was the vehicle for the research. All fourteen students attended practical and theoretical sessions based at the University, focusing on e-learning and hands-on sessions learning about various online communication tools such as blogs, wikis and discussion forums. As part of the module, they also worked with a class of 30 children (ages 8-10), creating online resources and activities in a shared Virtual Learning Environment (VLE). The student teachers engaged the children in online discussion and chat based upon the themes of e-safety and caring for their environment. In the process of working with the children, a range of online content was generated that contributed to the data set used for analysis (Table 1). The student teachers also posted reflections on their work with the children to a discussion forum. Joe, Karen, Maria, Laura and Heather, who became the focus of the study were randomly selected to participate in narrative interviews that were conducted after the completion of the module to mitigate any ethical compromises with regards my marking of the students' academic work. As sole researcher on the project I felt this was important both in terms of my ethical responsibilities to the student teachers' academic trajectory on the degree course and 
my responsibilities as an insider-researcher. The narrative summaries that were generated from my initial analysis of the data were also shared with the five student teachers for them to comment. Ethical issues were mitigated as far as possible through adherence to the University of Brighton's ethical guidelines together with the revised ethical code of the British Educational Research Association (BERA, 2004) and the student teachers were kept informed of the progress of the research at stages throughout the study. The dataset used for analysis is set out in Table 1 below.

\begin{tabular}{llllll}
\hline Student teacher & Karen & Maria & Joe & Laura & Heather \\
\hline $\begin{array}{l}\text { Baseline questionnaire } \\
\text { Online discussion }\end{array}$ & 1 & 1 & 1 & 1 & 1 \\
$\begin{array}{l}\text { postings } \\
\text { Online chat postings or }\end{array}$ & 0 & 33 posts & 40 posts & 104 posts & 46 posts \\
messages & 25 posts & 13 Posts & 0 & 0 \\
Personal reflections & 3 & 3 & 2 & 2 & 1 \\
Screenshot VLE content & 1 & 1 & 1 & 1 & 1 \\
Narrative Interview & 1 & 1 & 1 & 1 & 1 \\
Written assignment & 2000 & 2000 & 2000 & 2000 & 2000 \\
Narrative summary & Words & Words & Words & Words & Words \\
Email response to & Words & Words & Words & Words & Words \\
narrative summary & Yes & Yes & No & Yes & Yes \\
\hline
\end{tabular}

Table 1: Participants and dataset (pseudonyms have been used)

\section{Objectives}

Whilst the method of sampling is acknowledged to limit this study, the random approach to sampling was justified I feel by the objective of the research and the nature of the research questions. Firstly, the objective of the research was not to generalise to the wider population regarding the appropriation of technological tools in education, but to build a rich picture of individual teachers' appropriation of technological tools from multiple perspectives and within an interpretivist paradigm. Secondly, the research questions also called for a focus on individuals' perceptions and experiences, as I wanted to explore two key questions, namely:

How do different mediating factors inter-relate to affect the development of teachers' online pedagogical practice?

How can we design a pedagogical and methodological approach that captures the tension and complexity between the technological, socio-cultural context and individual agents?

Thus the aim of the research was to explore particular incidences, no less valid, of how differently, processes such as mediation and convergence can be perceived and experienced by different individuals. From this perspective processes such as 
mediation and convergence were conceived as theoretical tools to help in our understanding of phenomena

Methods

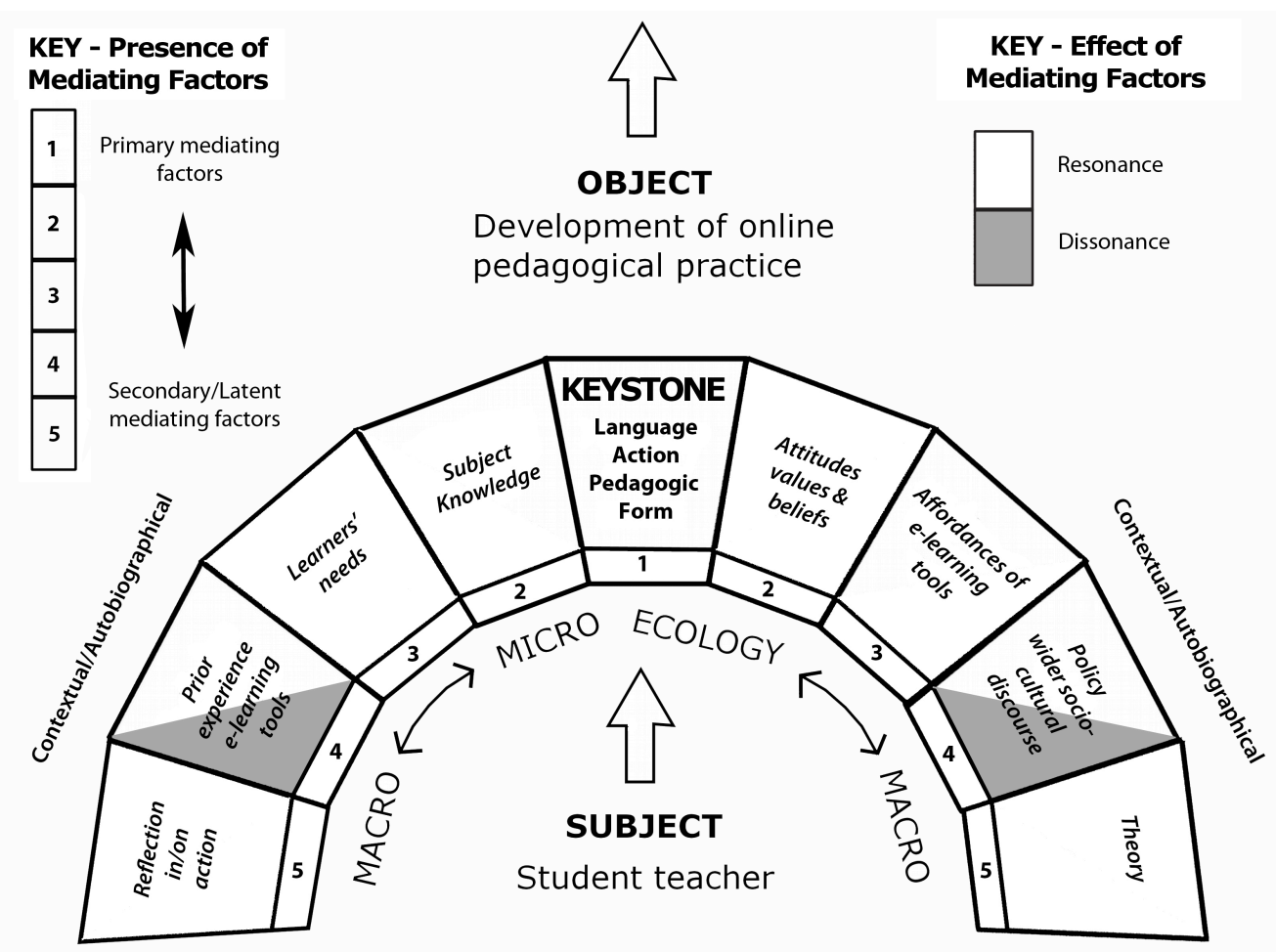

Figure 1: Narrative ecology framework identifying variables

The aim of the methodological design was to construct a rich within-case narrative ecology for each student teacher. From this perspective it was important to embed, rather than disconnect, the variable themes that emerged from the data within each student teacher's narrative ecology. I wanted to avoid embarking on an analytical journey of what Schostak calls 'relentless abstraction' (2002, p.22). Thus the narrative ecology model was used, as represented in Figure 1, to develop a nuanced narrative of each student teacher's case. The model illustrates the array of variable categories generated from the initial analysis of the data and arranged as an arch. During the narrative interviews the student teachers were asked to reflect on the professional intervention with the children using a common set of prompts such as 'can you describe the online conversations with the children and how they responded?' However, space was also required to enable the teachers to express 'the qualitatively different ways' in which they experienced and perceived the professional intervention (Richardson, 1999, p.53). This was achieved through more open-ended questioning inviting them to discuss their use of social networking tools outside of their professional practice, how they are 'interwoven with life offline,' (Merchant, 2011, p.11) and their beliefs about effective pedagogies. This aspect of the interview process took on a more narrative character, as the student teachers were invited to 'fill 
in the gaps' and were positioned as 'the expert in their own ways of seeing' (Schostak, 2006, p.149).

The structure of the analytical model is also significant (Figure 1). The teacher (Subject) and their pedagogical keystone is located at the centre of the process of professional development (Object), which is conceived of as an ecology of various micro and macro-level mediating influences and tools both shaping and being shaped by the individual teacher. The pedagogical keystone is defined here as the pedagogical foundations the teacher constructs in their aim to impact upon their learners, drawing on the various mediating factors surrounding the context. The closer a particular variable mediating factor such as 'prior use of e-learning tools' or 'subject knowledge' is located to the teacher's pedagogical keystone the more of a priority that variable appeared to have for the student teacher within the context of the intervention. Similarly, each variable within the arch shape was conceived of as impacting or being impacted on other variables within the ecological framework. This is expressed by the way a variable might have a resonant or dissonant effect within the overall ecological framework. In Figure 1 the variable 'prior use of e-learning tools' is partially shaded indicating it has both a resonant and dissonant effect on the overall narrative ecology. An explicit example here could be a teacher whose prior experience of using e-learning tools enables them to use the tools to motivate the children but who is so focused on the technological tools that important opportunities to develop children's subject knowledge and understanding are missed. In these ways the narrative ecology model enabled a more nuanced and teacher-centred analysis of the data.

The narrative ecology framework, I argue, offers a potentially more agent-centred lens through which to make sense of individuals' variable and complex engagement and activity over time in fluid and convergent social and professional networks characterised by symbiotic interplay and interdependency. Others have highlighted the importance of agents' autobiographical trajectories in terms of their adoption and appropriation of technological tools (Loveless, 2003: Daly and Pachler, 2009). As Daly and Pachler note, the process of appropriation is highly varied, as agents demonstrate variable 'histories of using technologies at work and in their home life' (2009, p.7). Merchant (2006, p.239) also identifies an ongoing narrative trajectory in agents' appropriation of technological tools linking this to notions of identity production 'through action and performance' as agents engage with technological processes such as blogging to synthesise and present a 'particular narrative (or narratives) of the self.' Consequently professional development is seen as a process of 'narrative cognition' (Bruner, 1990) that, like Jenkins' view of culture, takes place over 'a period of prolonged transition' (Jenkins, 2006, p.11). From this perspective, narrative is an important tool for tracing agents' underlying past experiences and ongoing motivations or what Bruner terms their 'configuring plot' (Bruner, 1990, p.43). The narrative ecology approach offers the potential for 'intimately broader theoretical understandings' of teachers' (Goodson, 2010, p.8) professional development with technological tools within wider political landscapes as they also seek to sustain 'their own identity across contexts' (Wenger, White and Smith, p.59).

There is not the scope within this paper to present a full narrative case of each of the five student teachers so I present a narrative summary through the filter of their 'prior experience of e-learning tools' and how these appeared to inter-relate with other 
mediating aspects within their narrative ecology, such as their response to their learners' needs as they perceived them, their attitudes and values or their positioning towards subject knowledge (Figure 1). This filter of 'prior experience of e-learning tools' is conceived broadly to incorporate social network sites and practices, and mobile devices; that is in line with the literature discussed hitherto learning is not confined by site, virtual or physical. I have further selected Joe and Karen for in-depth consideration in this paper as their contrasting backgrounds do I feel make for an interesting juxtaposition. In the concluding discussion I draw on some other critical incidents that emerged from the other narrative cases during the study and professional intervention.

\section{Within-case summary: Joe}

Joe was in his early twenties and had successfully completed three school-based placements prior to engaging with the project and module. Throughout Joe's narrative case it became apparent that his prior experience of e-learning tools (Figure 1) was firmly rooted in his social life and the use of social networking tools. He was a regular user of social networking sites such as MSN and Facebook as he revealed in his interview and his survey responses. Furthermore, a significant prior experience of using social networking that had impacted upon him was his setting up of a group area on Facebook as a member of the organising committee for a ski trip in the University Snowboarding and Ski Club. In the interview Joe revealed more about his motivation for using Facebook as a tool to organise the trip. Although it had been a time-consuming activity he had engaged in, it had also been rewarding in terms of providing an opportunity for members of the snowboarding and ski club to share in the excitement about their future trip, get to know people beforehand and then share their experiences afterwards as this extract from the interview conducted with Joe illustrates:

Joe: FaceBook takes up my life (laughing...) erm I think it's a good way to while away time (ironically) ... it just seems to fly away time when I'm using Facebook. I mean all of my friends are on it now. I share images... of my ski trip. Within the University we set up a group so that beforehand we could meet each other.... and then afterwards we'd share and reminisce.....post images of the holiday and videos. Yeh erm I mean I use it quite heavily and I set up doing things and playing games.

KT: Hmm it's interesting you say you set up a group on FaceBookfor the trip. What's the kind of incentive? What do you get out of that?

Joe: Well as web administrator on the committee it's just to make people feel included and if they're part of a group it's like oh yeh and they start to get excited before we go and so like it's the anticipation of what's to come and........people who've been on trips before can say oh yeh it's really good this has happened. And then afterwards just sharing because there was about 140 people and like almost 2000 photos (laughing).

(Narrative Interview)

Thus, Joe's motivation for using Facebook in this way was to 'make people feel included' in the preliminary phase of the trip, and to facilitate the sharing of 
experiences both before and after the trip. Joe's perceptions of social networking tools as an aid to inclusion and shared experience, were echoed throughout his experience of the professional intervention, using the tools in the school-based context. It was clear that his prior experiences of social networking and e-learning tools were a primary mediating influence (Figure 1).

This was seen in his approach to the intervention from the start. Joe and his partner dedicated the first session with the children to familiarising them with the VLE and its tools, focusing mostly on social exchanges and responding to whatever the children brought up in way of discussion about themselves. This focus on the social aspects of using the tools from the start was seen in the opening child-centred discussions with the children which took on an informal character that almost 'teased' the children into contributing and responding in the way that an online exchange between familiar friends might evolve in a social network as illustrated in the following transcribed extract from the discussion forum in which formal conventions of written language are relaxed by both the student teacher and the children:

Child 1: My best tv programme is horied henry

Child 2: MY FAVORITE PROGRAM IS CHAMPONS LEUGE LIVERPOOL 8 BL BL $B L B L 0$

Student Teacher: ***** im sorry to say this but it was a lucky result. Remember manu 7 roma 1, that's a result to jump up and down about. But well done Liverpool for doing something right. he he

(Transcribed from discussion forum)

In this sense, Joe and his partner's approach to the use of the tools with the children was responsive to the children's needs (Figure 1) in that it enabled them to become familiar with the tools they were going to be using in later sessions and helped to orientate them to the online environment. That is, informal uses of language found in social networks converged within this formal professional intervention as Joe and his partner prioritised the need for the children to become familiar with the tools over other aspects such as subject knowledge. This was clearly Joe and his partner's intent in the early stages of the intervention as they remarked in the text posted on their front page 'we need to make sure you all know how to use Moodle.' However, Joe and his partner's own ease at using social networking tools appeared to resonate further with their intentions here in that the response from the children was positive. The children took to the tools easily and also developed the confidence to explore other tools such as the instant messaging facility within the VLE. Joe referred to this phenomenon in his interview and again what was evident was the ease with which Joe responded to the children exploring the instant messaging function within the VLE. For other student teachers involved in the intervention the children's use of Instant Messaging was a point of tension due to the inability to either control whom the children messaged or steer the conversations. On the contrary, Joe had a more pragmatic approach in this respect and perceived instant messaging as a way of contacting the children individually and more directly in order to focus their responses to the subject-focused sessions later in the intervention as illustrated here in his responses during the interview when reflecting on the discussions and the children's use of instant messaging: 
KT: So this tension between what you say on task and off task. How would you describe what is on task for you?

Joe: Well for what I wanted them to do then was complete the work I'd set ... the quizzes....like that. I suppose they were learning even without doing the work I'd set like the topics....they were still learning how to use Moodle and interacting with each other...because I mean ***** was online up here (at university) and I was there faceto-face....so getting them to sit down and stay in their seat. Then when I was up here (at university) ***** was away so it was a bit harder. I had to try and keep them on task by erm making it more interactive and more engaging...making it more interesting to them and messaging them more because that's what I realised they enjoyed doing. So I did it through that way...they'd speak to me and respond that way.

(Narrative Interview)

That is, in response to Joe being based at the University and his partner who was meant to be in school being absent, Joe adopted the use of the instant messaging tool himself to exercise greater teacher presence within the online session. He was able to contact the children individually, as a teacher might use targeted questioning in the face-to-face classroom environment. That is, realising they were motivated by the use of this tool he adopted it and used it to focus the children on the tasks as well as manage any issues he perceived there might be in the classroom setting. This was evidenced in the trail of messages between Joe and individual children. At the end of the first session with the children he used the Instant Message facility to send a message directly to each child in his group informing them of the task for the following week. Similarly, when he realised two children were sharing a computer he was concerned that without his fellow student teacher present in the school to ensure that the two children had an equal opportunity to contribute to the session he used this more direct form of messaging to enquire if they could find a computer each. For example:

Joe: Hello ***** and $* * * * *$ are there not enough computers for you to have one each?

Child: No but I can go downstairs

(Instant Message Exchange)

In this way Joe was selecting his use of the e-learning tools to meet the needs of the children (Figure 1) in his group as they changed, taking a pragmatic approach to the tools. Thus, Joe's prior experience of using social networking tools to facilitate the organisation of the University ski trip was echoed in his use of the e-learning tools within the professional intervention. His prior experience of social networks appeared consistent with his ability to respond to the needs of the learners through adopting different online tools for different purposes. Both his social networking practices and his use of the tools within the professional context were characterised by a desire for inclusive practices and the motivation to facilitate increased levels of interaction amongst participants, although the interactions were not always focused on the subject content of the intervention. In this way, Joe's social networking and professional practices appeared to converge with particular characteristics and 
motivations being traced within both contexts and colouring the professional intervention according to Joe and his partner's intentions.

\section{Within-case summary: Karen}

Karen was a mature undergraduate student and like Joe had successfully completed three school-based placements during the course. In contrast to Joe, patterns of convergence between social networking and professional practices in Karen's case were more complex and revolved around a more critical and reflective approach to the adoption of the technological tools as will be discussed. Nevertheless, a characteristic that could be traced across her social networking and professional practice was, a pragmatic and utilitarian approach to the technological tools in both professional and social networking contexts, not dissimilar to Joe in this sense but guided by very different principles and concerns. It is important to stress that this is not meant as a value judgement but simply defines a pattern that emerged in Karen's appropriation of the technological tools in accordance with the extent to which they appeared to serve her perceived needs or the needs she perceived for the children she was teaching (Figure 1). For example, in response to baseline survey questions regarding her mobile phone use, her mobile phone appeared primarily useful in terms of the functions it enabled her to perform such as 'contacting friends, making bookings, a clock/stopwatch/alarm, and transferring files between devices'. Her perception of its use appeared particularly utilitarian, serving very specific and practical functions. She did use social networks such as MSN 'to keep in contact to an extent with some friends [I] see rarely' but this was not their primary function. This pragmatic and utilitarian approach was also reflected in her use of social networks such as Facebook. Karen indicated that she found this particularly useful for reading 'other student perceptions of observations' and 'feedback from school visits.' Although this was obviously embedded within her professional concerns, social networks also performed the function of enabling her to remain in touch with fellow student teachers and find out how they were getting on whilst on teaching practice. This convergence of the social and professional was also evident in the interview with Karen. When she was asked about her use of social networks they seemed to perform a similar function of updating or being updated by her student-teacher colleagues on progress with assignments as evident in the following extract:

Karen: Yes I use it a little bit but I can't pretend to understand a lot of these things that are going on [presumably referring to some of the social networking tools within Facebook].

\section{$K T: O K$}

Karen: whilst these assignments have been going on I've been updating people by saying 'only 200 words to go!' or 'only a conclusion away.'

KT: OK so you make reference to your professional life in those social networks?

Karen: Yes

(Narrative Interview)

This utilitarian approach to social networking could also be traced in her perception of the school-based professional intervention and the various strategies she adopted 
when working with the children. In contrast to Joe and his partner, Karen and her partner did not dedicate any time within the intervention to getting to know the children or orientating them towards using the tools within the VLE. Analysis of Karen and her partner's VLE home page showed a focus on subject-related content. They repurposed video news reports featuring school children from the BBC website about the issue of getting to school safely using environmentally friendly means. These were embedded into the VLE. They also provided a discussion forum focused on the subject matter 'Walking to School' with various prompts to elicit responses from the children. Although they provided a social forum for the children little time was given to social interaction within the dedicated time of the intervention. Karen and her partner expected the children to access the social forum in their own time. Also, the more interactive activities such as a quiz and links to a games website about road safety were placed lower in the online activity hierarchy than the other resources and activities. As well as being apparent from the organisation of the home page this utilitarian focus from the outset on the subject matter (Figure 1) emerged in the interview conducted with Karen. When asked why she had chosen to use video she commented:

"Em...I searched for just a short clip really that might focus the subject matter. ...which I thought....we were talking about walking to school and the safety aspects about walking to school think that could be a wide range in terms of personal safety.... when could they go? Could they walk? Traffic safety....road traffic.... Roads around schools, parking issues... the two clips they varied slightly but both [the two video news clips uploaded] had school, parking... getting to school issues and how two schools dealt with it differently." (Narrative Interview)

That is, the video clips were chosen primarily because of the need to 'focus the subject matter.' Similarly, although they had also made links to websites containing interactive games based around the subject matter, these games were perceived by Karen to detract from the issues. For example, commenting on the games Karen remarked in the interview:

"Em I think they enjoyed them but certainly [laughs to self] when they got onto the road safety website...the games that were in there although we didn't let our little group go on them straight away... when they saw others playing games they were like can we do that?" (Narrative Interview)

That is, Karen restricted the children's access to these games in the first instance feeling that they did not serve the function of their lesson objectives as well as the other content and activities they had provided for the children through the VLE. That is, the tools within the VLE were seen primarily by Karen as a means to deliver subject-related content (Figure 1) to the children echoing her approach to social networks as a means to deliver or receive updates and information. For example, she commented further in her interview:

"In the right environment I can see that being able to get information to students that you want to and for them to share you know if there's queries and things over what they're meant to be doing I can see how that can work." (Narrative Interview) 
Furthermore, Karen's utilitarian perception of the technological tools was also a point of critical tension. Whilst Karen perceived there to be potential within what the elearning tools such as discussion forums might yield, she was disappointed by the response of the children within the discussion forum. She commented in the interview that 'it was quite limited the actual conversation that was actually had.' Again this perception seemed to be influenced by the primacy she gave to the importance of subject knowledge within the intervention. She identified a gap between the thought processes she witnessed at first hand when the children were discussing their responses face-to-face, and the actual content of the written responses the children made in the online discussion forum. As she remarked in her interview:

"When it came to typing it in it was one.....maybe two-word answers or very limited so didn't really reflect what the thought processes had been." (Narrative Interview)

Concerned with the pace of some of the children's typing and the shortness of their replies Karen resorted to typing for some of the children when she was working faceto-face with the children. This way she felt that the written text would indicate more the quality of the thought process she had experienced in face-to-face discussion with the children. This was also evidenced in the longer responses given by the children when Karen was typing for them.

For Karen, the use of the discussion forum by the children did not function adequately to convey the children's understanding of the subject matter. Although it had provided a catalyst for face-to-face discussion of the subject matter the fact that it did not always reflect the depth of the children's thinking was problematic. Karen's more critically reflective perceptions, compared to Joe, of the intervention were also seen in her stance towards social networking tools. For her, the discussion forum within the VLE did not function adequately as a tool for conveying the children's thoughts and understanding.

Further evidence of convergence between Karen's prior experience of e-learning tools (Figure 1) through social networking practices and her professional practices with technologies emerged in some of her critical concerns that Karen shared with regards the appropriateness of working online with children. Karen had significant reservations about the age appropriateness of engaging in online discussions with younger KS2 children. However this concern also appeared to be linked with her wider attitudes and values (Figure 1) about the use of social networks by young people in general. Since engaging in the module to develop her online professional practice, she confided that she had signed up to Facebook to find out more about social networks. However, her experiences since signing up to Facebook had compounded her reservations about the appropriateness of such forms of communication for young people. A daughter of a friend had approached her online, which had concerned her for the following reasons given in her interview:

"a twelve year old has invited me to be her friend and I thought there was an age restriction... when I challenged her, she's lied about her age....I have not accepted her because I've seen material that I don't think is acceptable for kids to access and er....I did ask her does her mum know who is also on Facebook so does understand...er whether she knows about it...she does but whether she realises the implications of er...." (Narrative Interview) 
Similarly she went on to remark:

"And what's interesting that the way some of these 12 year old girls you know they've only got to stand a little way back from the camera and their age is not that er obvious so that's a worry. " (Narrative Interview)

It is clear from these responses that Karen's concerns about the age appropriateness of using online discussion with primary-age children within educational settings stemmed not only from her concerns about its efficacy in terms of subject knowledge (Figure 1) but also from more latent concerns regarding the wider socio-cultural discourse around e-safety and safeguarding children and her attitudes and values with regards to these issues (Figure 1). Her experiments with social networking outside of her university course had confirmed some of her apprehensions about children's vulnerability online. The extent to which this affected her approach to the intervention as a whole is difficult to quantify but the interplay between her professional use of online communication tools and her own experience of social networking was rooted in a wide ecology of factors including her pedagogical beliefs and values regarding the age appropriateness of working online with primary school children influenced by the latent socio-cultural discourses around e-safety and social networking.

\section{Cross-case discussion}

In Joe and Karen's cases convergence was seen in the arbitrariness of boundaries between social network and professional practices (Katz and Aakhus, 2002; Jenkins, 2006; Horst, 2008; Pachler et al, 2010). However, this was particularly evident in the ubiquity seen with regards the formation of different dispositions across both professional and social network contexts. Joe's attitudes and values (Figure 1) about facilitating an 'inclusive' online environment were evident across both contexts with his prior experiences of using Facebook to help organise a University trip appearing to echo his approach to the professional intervention with the children. Similarly, Karen's critical reflections regarding the professional e-learning environment was a trait that could be traced within her explorations of social networking sites. These findings support arguments regarding increased fluidity between contexts (Katz and Aakhus, 2002; Jenkins, 2006; Horst, 2008; Pachler et al, 2010).

Such fluidity was also seen during the professional intervention in the other cases. As the student teachers were working in pairs at different sites they frequently communicated with their partner based online using their mobile phones to text each other. Furthermore the use of their mobile phones was integrated with their pedagogical intentions. Heather related in her narrative interview how she had received a text from her partner in school because she wanted to change the order in which the children tackled the online activities they had planned. This had taken her by surprise as she remarked 'I was thinking that my partner had the same expectations that I had but then I got a text that said "put the games on." From this perspective, the use of their mobile phones by the students during the intervention had increased the provisionality (Baron, 2008) of both the online resources they had developed for the children, and their agreed expectations or plans for the lesson. Thus the convergence of contexts afforded by the online environment of the VLE together with the near real-time communication between the two teachers via their mobile phones, appeared to increase the provisionality of the pedagogical timescales in the classroom. 
However, whilst Baron has argued that such convergence through technologies and restructuring of the time people spend together, can lead to the 'end of anticipation' (Baron, 2008, p.7), it is interesting that Heather over-rode her partner's request and used the anticipation of the interactive online games as a pedagogical lever to elicit more responses from the children; for example posting in the discussion forum 'before I open the game can you tell me something you know about keeping safe online?' From the perspective of Cuban's findings (2001), both of these teachers were indeed using the technologies in ways that 'sustained rather than transformed' their pedagogical principles. That is Heather exerted her active agency over the context (Pachler, Cook \& Bachmair, 2010). Both student teachers' pedagogical principles were clearly very different and were brought into tension by the ways in which the use of the technologies restructured the pedagogical timescales or rendered them more provisional (Baron, 2008). Despite this, Heather's individual agency over the context prevailed.

Another important question that this paper and the two cases presented raise, concerns the design of and research into experiences with social network tools and mobile media. The development of a narrative ecology approach for capturing and making sense of agents' actions as they engage in increasingly convergent contexts, social and professional, afforded by mobile technologies within always-on communications networks appeared productive. There were commonalities between the ways in which all of the teachers appropriated the tools for pedagogical purposes. This was often reflected in quite pragmatic and utilitarian approaches, using the technologies to achieve specific goals such as eliciting more responses in the discussion forum with the anticipation of playing an interactive game (Heather), or messaging the children directly to ensure that they were getting an equal opportunity to access the computer (Joe). While all of the teachers demonstrated pragmatic and utilitarian approaches to the pedagogical uses of the technologies at various stages throughout the intervention they were nevertheless motivated by different 'concerns and ambitions' (Säljo, 2009, p.316). Again, their individual agency over the contexts in which they were operating appeared significant and the design of the narrative ecology model was a useful tool in highlighting such user agency over contexts.

This individual agency could be evidenced evidence in both Joe and Karen's cases, in terms of an ongoing narrative trajectory (Merchant, 2011) or a 'configuring plot' (Bruner, 1990, p.43). Engaging in the professional intervention had prompted Karen to find out more about social networking. That is, engagement in the professional intervention using social networking tools for educational purposes had prompted a shift in Karen's approaches to social networking in general. In contrast to Karen, Joe's narrative trajectory was more constant. This was apparent in the way in which his philosophical principles towards the use of social networks as a tool for engaging and including others as part of a shared social experience were sustained (Cuban, 2001) in his approach to using the tools for pedagogical purposes sometimes at the expense, it could be argued of the opportunity to model more formal yet accessible ways of communicating online with children. Neither teachers experienced a significant transformation of their pedagogical practice but their experiences were 'highly varied' echoing aspects of their distinctly different past experiences (Daly and Pachler, 2009, p.7) and highlighting the significance of their agency over the process of professional development. 


\section{Conclusion}

While there are limitations with the scope of this study, which I have indicated, it is clear that the different teachers' experiences of convergence were highly individualised and mediated by a range of factors. Also, whilst there was no evidence of any causal link between the teachers' wider, prior experiences of social network tools and their professional practice, there was evidence of congruency in their individual dispositions to the technological tools across contexts. Such individually nuanced yet interconnected factors mediating pedagogical practice with technological tools support calls for a cultural ecology that places individual narratives of mediated activity within the broader cultural ecology of mass communication in order to offer a fuller picture of the interplay involved as agents utilise technological tools in different contexts (Werstch, 1998: Davydov, 1999: Pachler et al, 2010: Cook et al, 2011).

Furthermore, if we are in 'a period of prolonged transition' with regards technological transformation as Jenkins asserts (2006, p.11) then agent-centred perspectives such as offered here are important for capturing and characterising the ways in which the process of convergence is experienced and perceived by those who have a vital role to play in integrating technologies and shaping future pedagogical practice be it within formal or informal contexts. As illustrated by Karen and Joe's cases their appropriation of technological tools was part of an on-going yet distinct narrative trajectory, wrapped up with the development of their identity across contexts (Merchant, 2006 \& 2011; Wenger, White and Smith, 2009). From this perspective narrative has the potential to bridge the arbitrary and convergent cultural boundaries (Katz and Aakhus, 2002; Jenkins, 2006; Horst, 2008; Pachler et al, 2010) around sites of learning and, developed further, could offer the 'intimately broader' understanding (Goodson, 2010, p.8) called for as agents' activities are dispersed across increasingly mobile and interconnected social, cultural and professional networks. This also challenges simplistic notions of convergence as a process characterised by causality from one context to another. My own findings concur with Boyd and Ellison's (2008, np) assertion that Social Network Site 'researchers' ability to make causal claims is limited.' Furthermore, what is being questioned here is the significance of causality in aiding 'scholars' ability to understand' the implications of social network tools and mobile technologies for education and professional development. Capturing and characterising the different ways in which convergence is perceived and experienced by those at the centre of the process would appear to be more significant in determining the extent to which 'for certain individuals, in particular setting[s]' technologies are being used in ways that either 'liberate or oppress' (Bruce and Hogan, 1998, np). It is clear that social network tools and new forms of mass media communication are significantly implicated in cultural shifts and convergence as the recent unfolding and continued struggle of the Arab Spring can attest. Asma Mahfouz's vlog (2011) uploaded to Facebook one day, went viral and became an international news story the next. It has since become an important historical marker in the on-going struggle for political power in Egypt. However, to examine this or any event incorporating social media only through the lens of causality and the affordance of social networks is to mitigate the rich micro and macro-ecology of such events. In order to work towards a richer understanding of the implications and issues surrounding social network sites and the implications for professional development, I conclude it is useful to conceive of convergence, in which they are significantly implicated as an agent-centred, cultural process first and a technological process second. 


\section{References}

Baron, N.S. (2008) Always On: Language in an Online and Mobile World. Oxford and New York: Oxford University Press.

Becta, (2009). Harnessing Technology Review 2009: The role of technology in education and skills. Coventry: Becta.

Boyd, D. M. and Ellison, N. B. (2007) Social network sites: Definition, history, and scholarship, Journal of Computer-Mediated Communication, 13 (1).

British Educational Research Association (2004), Revised Ethical Guidelines for Educational Research. Available from http://www.bera.ac.uk/publications/ Accessed 10 $0^{\text {th }}$ March 2012.

Bruner, J. S. (1990) Acts of Meaning, London: Harvard University Press.

Bruce, B. C. and Hogan, M. P. (1998) The Disappearance of Technology: Towards an Ecological Model of Literacy, in Reinking, D. McKenna, M. C. Labbo, L. D. Kieffer, R. D. (Eds.) Handbook of literacy and technology: Transformations in a post typographic world, New Jersey: Routledge

Castells, M. (Ed) (2004) The Network Society: A Cross-cultural Perspective, Cheltenham: Edward Elgar Publishing.

Cook, J. Pachler, N. Bachmair, B. (2011) Ubiquitous Mobility with Mobile Phones: a cultural ecology for mobile learning, E-Learning and Digital Media, 8 (3), 181-195.

Cuban, L. (2001) Oversold and underused: Computers in the classroom, Cambridge, Massachusetts: Harvard University Press.

Daly, C. Pachler, N. \& Pelletier, C. (2009) Continuing Professional Development in ICT for Teachers: A literature review. Coventry: Becta.

Davydov, V. (1999) The content and unsolved problems of activity theory. In: Engestrom, Y. Miettinen, R. \& Punamaki, R. L. (eds.) Perspectives on Activity Theory. Cambridge: Cambridge University Press.

DfES (2005) Harnessing Technology: Transforming Learning and Children's Services, London: DfES.

Fisher, T., Higgins, C. \& Loveless, A. (2006) Teachers Learning with Digital Technologies: A review of research and projects, Bristol: Futurelab Goodson, I. F. Biesta, G. J. J. \& Adair, N. (2010) Narrative Learning, Oxon: Routledge. 
Horst, H. A. (2008) Blurring the boundaries: connectivity, convergence and communication in the new media ecology, Beyond Current Horizons, Bristol: Futurelab.

Jenkins, H. (2006) Convergence Culture: Where Old and New Media Collide, New York: New York University Press.

Katz, J. and Aakhus, M. (Eds) (2002) Perpetual contact: Mobile communication, private talk, public performance, Cambridge: Cambridge University Press.

Loveless, A. (2003). The interaction between primary teachers' perceptions of ICT and their pedagogy. Education and Information Technologies, 8 (4) 313-326.

Luckin, R. (2008). The learner centric ecology of resources: A framework for using technology to scaffold learning. Computers and Education, 50 (2), 449-462.

Merchant, G. (2006). Identity, Social Networks and Online Communication, E-Learning and Digital Media, 3 (2), 235-244

Merchant, G. (2011). Unravelling the social network; theory and research, Learning Media and Technology, Online first, 1-16.

McLuhan, E. \& Zingrone, F. (Eds) (1995). Essential McLuhan, London: Routledge.

McLuhan, M. (1964). Understanding Media, London: Routledge.

Pachler, N. (2009). The socio-cultural ecological approach to mobile learning: an overview. In: Bachmair, B. (ed.) Medienbildung in neuen Kulturräumen: Die deutschprachige und britische Diskussion. Wiesbarden: VS Verlag für Sozialwissenschaften.

Pachler, N. Cook, J. \& Bachmair, B. (2010). Appropriation of mobile cultural resources for learning. International Journal of Mobile and Blended Learning, 2 (1), 1-21.

Postman, N. (1992). Technopoly: The Surrender of Culture to Technology, New York: Vintage Books.

Schostak, J. (2002) Understanding, Designing and Conducting Qualitative Research in Education, Buckingham: Open University Press.

Schostak, J. (2006) Interviewing and Representation in Qualitative Research, Maidenhead: Open University Press

Säljö, R. (2009) Videopapers and the emergence of analytical perspectives on teaching practices. Technology, Pedagogy and Education, 18 (3), 315-323.

Turvey, K. (2012). Constructing narrative ecologies as a site for teachers' professional learning with new technologies and media in primary education. E-Learning and Digital Media, 9 (1).

Wertsch, J. V. (1998). Mind as Action, New York and Oxford: Oxford University Press. 
Turvey, K (2012) British Journal of Educational Technology, 43:5, Author's Post Print Copy

Wenger, E. White, N. and Smith, J. D. (2009) Digital Habitats; Stewarding Technology for Communities, Portland: CPSquare. 